\title{
Biojurídica: una necesidad para las nuevas tecnologías aplicadas a la vida humana*
}

\section{Agustín Antonio Herrera Fragoso**}

\begin{abstract}
RESUMEN
Este artículo brinda al lector una base de conocimiento y reflexión de una nueva disciplina jurídica denominada "biojuridica", pasando por su complemento "bioética", donde permite distinguir y analizar la necesidad jurídica sobre la aplicación de las nuevas tecnologias que tiene un impacto directo sobre la vida humana; buscando fundamentos principialistas y transdisciplinar, para obtener un resultado integral y más adecuado.
\end{abstract}

PALABRAS CLAVE

biojurídica, bioética, principios, tecnología, ciencia.

\begin{abstract}
This article provides the reader with a knowledge base and reflection of a new legal discipline, called "biolaw", through its "bioethics" complement, where it allows to distinguish and analyze the legal need for the application of new technologies that have a direct impact about human life; looking for principialist and transdisciplinary foundations, to obtain an integral and more adequate result.
\end{abstract}

\section{KEYWORDS}

Biolaw, bioethics, principles, technology, science.

*Artículo de Investigación postulado el 12 de febrero de 2020 y aceptado el 27 de julio de 2020

**Profesor investigador en el Instituto de Ciencias Jurídicas de Puebla A.C., México. (agusfrag80@hotmail.com) orcid.org/0000-0002-2401-6141 


\section{SUMARIO}

1. Introducción

2. Bioética

3. Biojurídica

4. Conclusión

5. Referencias Bibigráficas:

\section{Introducción}

"Incluso en la más encarnizada lucha

De nuevas y antiguas fuerzas, Nacen medidas justas $y$ Se forman proporciones sensatas." Carl Schmitt

Previamente es indispensable señalar que esta nueva disciplina jurídica, surge de la evolución que tienen las nuevas tecnologías en la intervención de la vida en general y la vida humana en particular, tecnologías bajo el esquema de mejoramiento humano o transformaciones diversas y direccionadas en la naturaleza humana, donde las nuevas tecnologías se pueden encausar para el uso terapéutico, mejoramiento humano, transformación o encausamiento evolutivo, aunque puede tener efectos indeseados o malignos, discriminación económica, biológica o hasta eugenésica, entre otros; de lo cual, el derecho no puede quedar ajeno a su delimitación, a lo que el derecho prima facie es insuficiente para determinar de forma justa la transformación y evolución de la ciencia y tecnología, basado en muchas ocasiones de peritajes o amicus curiae- que en la mayoría de los casos tienen intereses subjetivos- sin conocimiento antropológico y ético, por lo que la resolución puede perder toda razón, inteligibilidad, violando los principios de razonabilidad y proporcionalidad.

Por lo que la biojurídica, nueva disciplina necesaria y complementaria de la bioética, ha pasado de ser una mera deontología profesional a regular cuestiones éticas en el campo de la investigación y de la aplicación biotecnológica sobre el ser humano, con la prevención y cuidado de los principios éticos y jurídicos que reforzarán y darán sentido a la zona gris que marcan actualmente la normatividad jurídica nacional e internacional, así como una guía argumentativa para las anomias y hermenéutica de temas límite. 


\section{Bioética}

"La Ciencia sin Conciencia no es más que la Ruina del Alma”. ${ }^{1}$ "La Conciencia que falta aquí no es la Conciencia Moral, es la Conciencia sin más, es decir, la aptitud para concebirse a si misma. Desde ahora, si queremos ser lógicos con nuestra intención, tendremos que asumir necesariamente el problema de la ciencia”.

"La humanidad requiere urgentemente un nuevo saber hacer que proporcione la inteligencia de cómo usar el conocimiento para la supervivencia del hombre y mejorar la calidad de la vida (...) esta ciencia de la supervivencia se debe construir sobre la ciencia de la biología, ampliada más allá de los límites tradicionales con el objeto de incluir elementos esenciales de las ciencias sociales y las humanidades, con especial énfasis en la filosofía en sentido estricto, con su significado de amor a la sabiduría. Una ciencia de la supervivencia debe ser algo más que solamente ciencia, y por tanto, propongo el término bioética para enfatizar los dos ingredientes más importantes en el logro de un nuevo conocimiento tan necesaria: el conocimiento biológico y de los valores humanos". ${ }^{3}$

Con este texto programático daba nombre Potter a esa nueva disciplina que se estaba gestando en los años setenta del siglo XX. Según el mismo Potter explicaría años más tarde, la palabra le vino a la mente al improviso, al unir dos términos: "bios", que representaría las ciencias biológicas; “ "ethics", ${ }^{4}$ una palabra con la que no aludía simplemente a la ética, sino a los valores humanos en general.

El sentido de la bioética, según Potter, era sencillo y apremiante: elaborar una ciencia orientada a garantizar la supervivencia humana en el planeta Tierra, a través del diálogo entre las ciencias experimentales y las ciencias humanísticas.

En otros escritos Potter llamó a la BIOÉTICA “wisdom of science” sabiduría de la ciencia, proponiendo que la dimensión técnico instrumental debía ir unida a la filosófico-sapiencial, supuso que nadie, antes que él, había usado la palabra bioética. Sin embargo, varios expertos están empezando a reconocer

\footnotetext{
${ }^{1}$ Rabelais, citado por Morín E. en el Método: La naturaleza de la naturaleza: Ediciones Cátedra. España, 6a. edición, 2001. ${ }^{2}$ Ídem.

${ }^{3}$ Cfr. Potter, V. R., Bioethics: Bridge to the future, Prentice-Hall Inc., Englewood Cliffs, New Jersey, 1971, pp. 1-2.

${ }^{4}$ Potter, V. R. Biotethics the science of survival, Perspertives in Biology and Medicine, 14.1970, pp. 127-153; Bioethics: bridge to the future, Englewood Cliffs: Prentice-Hall, New York 1972.
} 
que el término ya había sido usado en $1927^{5}$ por un teólogo alemán, Fritz Jahr, que publicó un artículo en la revista "Kosmos" (Vol. 21, pp. 2-4), titulado Bioethik: Eine Umschau über die ethischen Beziehungen des Menschen zu Tier und Pflanze ${ }^{6}$ (Bio-ética: una panorámica sobre la relación ética del hombre con los animales y las plantas). Años más tarde, en 1934, Jahr publicó otro trabajo donde volvió sobre la noción de "Bio-ethik": Drei Studien zum 5. Gebot, en la revista "Ethik. Sexual und Gesellschaftsethik" (Vol. 11 (1934), pp. 183-87). ${ }^{7}$

La idea de Fritz Jahr ${ }^{8}$ era sencilla: inspirado en los famosos imperativos éticos de Kant, quería subrayar la importancia de un "imperativo bioético" que orientase correctamente nuestro comportamiento respecto de todos los seres vivos. Es casi seguro que Potter no conocía a Jahr y que de buena fe creía haber descubierto una palabra a la que dio un sentido diferente del que había dado Jahr. De haber conocido Potter la obra de su predecesor seguramente lo habría citado y estudiado con interés.

Son varios los trabajos que empiezan a reconocer la importancia de las ideas de Fritz Jahr. Uno es un opúsculo publicado en 2007 por Hans-Martin Sass, que lleva como título Fritz Jahr's Bioethischer Imperativ. 80 Jahre Bioethik in Deutschland von 1927 bis 2007. En esta publicación se recogen los dos textos de Jahr (el de 1927 y el de 1934). ${ }^{9}$

Etimológicamente proviene del griego bios y ethos, ética de la vida. ${ }^{12}$ Bajo la denominación de Bioética en su obra citada, Potter propuso que se constituyera una nueva disciplina "cuyo objeto formal sería el problema de la supervivencia de la humanidad, sirviendo de puente entre la ética clásica y las ciencias de la vida, tomando la vida en el sentido más amplio de la palabra". ${ }^{10}$ Pero, aunque el inventor del término fue Potter, su sistematizador académico y divulgador fue Hellegers que en 1971 programó académicamente esta nueva disciplina en la George town University de Washington. No se desestima que Hellegers también introdujera el término bioética sin vincularlo a Potter, pero con un sentido menos amplio que el utilizado por Potter.

\footnotetext{
${ }^{5}$ Cfr. Hans-Martin, Sass, Fritz Jahr's 1927 Concept of Bioethics, Kennedy Institute of Ethics Journal 17, 2008, pp. 279-295.

${ }^{6}$ Cfr. Goldim, José Roberto, Revisiting the Beginning of Bioethics: The Contribution of Fritz Jahr (1927), Perspectives in Biology and Medicine 52, 2009, pp. 377-380.

${ }^{7} \mathrm{Cfr}$. Lolas, Fernando, Bioethics and animal research. A personal perspective and a note on the contribution of Fritz Jahr, Biological Research 41 (2008), pp. 119-123.

${ }^{8}$ Natacha, Salomé Lima, Fritz Jahr y el Zeitgeist de la bioética, Aesthethika 5 (2009), pp. 4-11.

${ }^{9}$ Se puede consultar en: http://www.ethik-in-der-praxis.de/MM-175.pdf. 04-10-09.

${ }^{10}$ Cfr. Blázquez, N., Bioética. La nueva ciencia de la vida. B.A.C. Madrid, 2000, p. 5.
} 
Así, este neologismo comenzó a difundirse y a ser relacionado con las instituciones científicas y académicas interesadas por los asuntos más polémicos de la reproducción humana, de la experimentación científica y de sus aplicaciones biomédicas más revolucionarias, pero al mismo tiempo, más inquietantes a nivel ético. Así la bioética se impuso pronto en la comunidad científica como una nueva disciplina humanística destinada a establecer una racional y precavida participación de los científicos en los procesos de investigación biomédica que plantean nuevos e inquietantes problemas éticos.

No obstante, en la constitución de este término y de esta disciplina no podemos perder de vista a un tercer personaje: H. Tristram Engelhardt, con su obra ${ }^{11}$ que ha contribuido a enmarcar el paradigma ético de la bioética dentro del modelo utilitarista de la postmodernidad. Por último, es propio citar a otros dos personajes que se les puede considerar también como fundadores de esta disciplina: Daniel Callaghan y Willard Gaylin. Ambos en la década de los sesenta en el Hastings Center de Nueva York prestaron atención a los problemas que surgieron en aquella época en el campo de la investigación científica y de la experimentación biomédica.

Como ejemplo: "En 1963, en el Jewish Chronic Disease Hospital de Brooklyn, en el curso de un experimento se habían inyectado células tumorales vivas a pacientes ancianos, sin su consentimiento. Entre 1965 y 1971, se llevó a cabo en el Willowbrook State Hospital de Nueva York una serie de estudios sobre la hepatitis viral, inoculando el virus a unos niños con discapacidad que estaban hospitalizados. Estos experimentos hicieron que se recordara con espanto la experimentación practicada en los campos de concentración de la época nazi”. ${ }^{2}$ Callaghan y Gaylin analizaron este panorama con el objeto de estudiar y formular normas en el campo de la investigación y experimentación biomédica.

Con lo dicho hasta aquí, podríamos afirmar que el término bioética hace referencia a una aplicación de la disciplina ética al campo de las investigaciones biomédicas. 0 como bien dice Sgreccia: “(...) es interesante subrayar el núcleo conceptual en que se fundamenta el nacimiento de la Bioética: la necesidad de que la ciencia biológica se plantee preguntas éticas, de que el hombre se interrogue sobre la relevancia moral de su intervención sobre la vida". ${ }^{13}$

Respecto a la definición en la primera edición de la Enciclopedia de Bioética, esta disciplina se determinó como "el estudio sistemático de la conducta

\footnotetext{
"Engelhardt, H. T. La fundamentación de la bioética. Paidós. Barcelona, 1995.

${ }^{12}$ Cfr. Sgreccia E., Manual de Bioética, Diana, México, 1996, p. 17.

${ }^{13}$ Idem.p.16.
} 
humana en el campo de las ciencias de la vida y del cuidado de la salud, conducta examinada a la luz de los valores y principios morales". ${ }^{14}$

Por su parte, A. Pessina, la ha definido como "conciencia crítica de la civilización tecnológica". ${ }^{15}$ La bioética es un retorno al concepto de ética como recta ratio agibilium a los dilemas que se plantean en la civilización tecnológica.

También se ha definido como la parte de la ética que se refiere a las cuestiones planteadas por el desarrollo de las ciencias biomédicas en los ámbitos de la vida y de la salud ante problemas nuevos o antiguos modificados por las nuevas tecnologías. Ha pasado de ser una mera deontología profesional a regular cuestiones éticas en el campo de la investigación y de la aplicación biotecnológica sobre el ser humano. ${ }^{16}$ Sobre éste particular, las nuevas biotecnologías se han dado a la labor de aplicarse en la nueva realidad biológica como son los casos de la clonación, manipulación genética y en particular en técnicas de reproducción asistida.

De lo dicho, se desprende que la bioética propone una reflexión sobre el valor de la vida humana y la dignidad de la persona desde presupuestos racionales y a la luz de los valores y principios éticos. Surge como respuesta a un malestar cada vez más tangible: el que experimenta el ser humano frente al fuerte carácter invasor de las biotecnologías y tecnologías modernas. Tal malestar parece incrementarse cuando más aumenta el número de cuestiones casuísticas de las que se encargan los bioéticistas y cuánto más se implican los juristas y los políticos en sus debates, donde su participación llega a ser prácticamente imprescindible y decisiva. ${ }^{17}$ La función de la bioética se orienta a la búsqueda de un deber ser específico de la medicina, de la investigación científica y de la aplicación de las nuevas biotecnologías a los seres humanos en el marco de la ética.

${ }^{14}$ Cfr. Reich, W. T. (ed.), Encyclopedia of Bioethics I. The Free Press, New York 1978, XIX. Ver las definiciones en Ruiz Retequi, Antonio. La Ciencia y la fundamentación de la Ética. Deontología Biológica, Facultad de Ciencias, Universidad de Navarra, Pamplona, 1987. Durand, Guy. La Bioética. Desclée de Brouwer. Bilbao, 1992.

${ }^{15}$ Cfr. Pessina, A., Bioetica L'uomo experimental, Mondadori, Milano 1999, p. 3. Riflette oggi sull origine della bioetica significa prendere atto di un proceso di ripensamento delle principali convinzioni che hanno retto e ancora reggono, lo sviluppo della civiltà occidentale. La biotica esprime, infatti in momento "critico": I'incrinarsi della fiducia nelle capacita di autoregolazione dei processi tecnologici e l'insoddisfazione nei confronti di alcuni criteri morali che hanno fatto da sfondo alla recerca e alla prassi scientifica.

${ }^{16} \mathrm{Cfr}$. Simón Vázquez, Carlos (director) Diccionario de bioética, editorial monte Carmelo, Burgos, España, 2006, p. 122.

${ }^{17} \mathrm{Cfr}$. D’ Agostino, Francesco, Bioética estudios de filosofía del derecho, ética y sociedad, en ediciones internacionales universitarias, Madrid, 2003, p. 14. 
Por lo señalado y tomando en cuenta la definición de la Dra. Elena Postigo Solana, ${ }^{18}$ con algunos cambios como el de inter a transdisciplinar, creo que es muy actual y que engloba de forma general a esta disciplina:

"La bioética es el estudio sistemático y transdisciplinar de las acciones del ser humano sobre la vida humana, vegetal y animal, considerando sus implicaciones antropológicas y éticas, con la finalidad de identificar racionalmente aquello que es bueno para el ser humano, las futuras generaciones y el ecosistema, para encontrar la mejor solución clínica o científica y elaborar una normativa jurídica adecuada”

Entendiendo por:

a) Sistemático: de carácter general. Por esto la bioética merece el estatus de disciplina; que en su fundamento se desglosa de la ética. La bioética es una ética aplicada a la ciencia y a la vida en general.

b) Transdisciplinar: porque intervienen en ella muchas otras áreas del conocimiento que se entrelazan entre ellas para obtener un juicio de razón, no desde sus parcelas de conocimiento de forma separada, sino complementaria hacia el mismo fin, en particular, el cuidado de la dignidad humana durante toda su existencia.

Para hablar de una disciplina o ciencia, es necesario determinar su objeto material y su objeto formal. Por objeto material entendemos que estudia esa ciencia o disciplina y por objeto formal entendemos bajo qué punto de vista lo estudia.

El objeto material de la bioética son las acciones del hombre sobre la vida in genere; en cambio, su objeto formal se enfoca desde la perspectiva ética, para ver si estas acciones son buenas y hacen al hombre mejor o, por el contrario, le producen un daño a él, a la humanidad o a las generaciones futuras, desde las evidencias científicas.

c) La bioética debería tener en cuenta también un concepto de responsabilidad a largo plazo, como aquel sugerido por H. Jonás en su volumen "El principio de Responsabilidad", ${ }^{19}$ para con los seres humanos actuales y para las generaciones futuras, reconocido ya por Aristóteles como

\footnotetext{
${ }^{18} \mathrm{Cfr}$. Tomas Gloria, Maria y Postigo Solana, Elena (coordinadoras), Bioética Personalista: ciencia y controversias, Madrid, España 2007, p. 16.

${ }^{19}$ Jonas, Hans, El Principio de responsabilidad: ensayo de una ética para la civilización tecnológica, edit. Herder, España, 1995.
} 
prudencia y en la actualidad como el principio de precaución (principio reconocido dentro de la biojurídica), que debería ser acogido por su importancia a nivel internacional como Ius cogens.

d) La finalidad de la bioética no es sólo reflexionar, sino fundamentalmente encontrar criterios, principios o normas que guíen el obrar del hombre respecto a la vida y elaborar leyes adecuadas que permitan el desarrollo y el progreso de la humanidad de forma racional (aquí ya se entrelaza la biojurídica).

La bioética está siendo una notable labor de reflexión y formación en temas que atañen al ser humano. Debe ser la bioética una filosofía de la ciencia médica que busca captar las peculiaridades epistemológicas y metodológicas de esta ciencia; o bien debe hacer una descripción evolutiva de los problemas o de los horizontes éticos planteados por el progreso inevitable de la humanidad y finalmente debe atender en cuanto ética, a orientar normativamente la acción del médico y en general de todo individuo que actué dentro del deber ser.

La bioética existe como intento de reflexión sistemática acerca de todas las intervenciones del hombre sobre los seres vivos; una reflexión tiene un objetivo específico y difícil de alcanzar, el de identificar los valores y normas en el actuar humano, la intervención de la ciencia y de la tecnología en la vida misma y en la biosfera deberán estar encausados para una perfecta armonía entre todos los actores implicados en la simbiosis de la vida, con un sustento de responsabilidad humana.

Mireille Delmas-Marty distingue entre humanidad (conjuntos donde la víctima es la humanidad entera) y especie humana (la dignidad de cada persona; la víctima es aquí individual). Jürgen Simon ha dedicado una especial atención a la dignidad humana como principio regulador en la bioética. ${ }^{20} \mathrm{El}$ criterio que oriente las intervenciones bioéticas deberá ser el de evitar cualquier posible catástrofe. ${ }^{21}$ De lo que se puede decir que, la bioética retoma los conceptos fundamentales de la ética griega: "Phýsis, naturaleza, éthos, costumbre, areté, virtud, y dikaiosýne, justicia. Entre todos tienen que reinar la isonomía, el equilibrio, la proporción; de lo contrario, aparece el predominio excesivo de un miembro sobre los demás". ${ }^{22}$

\footnotetext{
${ }^{20}$ Fundación de ciencias de la salud: en las fronteras de la vida: ciencia y ética de la clonación, decisiones doce calles, S.L., Madrid, 1998.

${ }^{21}$ Jonas H., Philosophical seáis. From ancient creed to technological man, Chicago, 1974.

${ }^{22}$ Cfr. Gracia, Diego, fundamentos de bioética, EUDEMA Universidad: manuales, Madrid, 1989, p. 27.
} 
En ese sentido, el médico, juez, político, legislador, científico y en general cualquiera operador deóntico, ha de ser filósofo, es decir, ha de atender las virtudes éticas (o morales) y dianoéticas (o lógicas) del amante de la sabiduría.

Ahora bien, desde la perspectiva de un estado social y democrático de derecho, con pleno respeto a las libertades y derechos fundamentales, la bioética ha de permanecer alejada tanto de los dogmatismos, como de las posturas escépticas y relativistas y transitar por el camino del diálogo pluralista, preservando siempre los mínimos éticos indispensables, la protección de valores humanos fundamentales y el reconocimiento de la dignidad humana. ${ }^{23}$

Dicho lo cual, es indispensable ver la interrelación que tiene con el derecho, deber que tiene que ser regulado para que los excesos en la intervención de las nuevas biotecnologías sobre la vida humana se rijan bajo el imperio de la ley, así como las reglas y principios de derecho aplicables, que los derechos humanos otorgan a todo ser humano.

\section{Biojurídica}

Cada uno de nosotros será justo en la medida que haga lo que le corresponde.

Sócrates. ${ }^{24}$

Para llegar al nacimiento de la Biojurídica conviene retroceder en el tiempo con el fin de conocer mejor cuáles fueron sus orígenes. Desde la más remota antigüedad las relaciones entre médicos y enfermos se han regulado por medio de artículos de las leyes generales que daban los gobernantes para regir a su pueblo.

En el año 2000 a. C., durante el reinado del rey Ur-Nanmmu, se promulgó el Código que lleva su nombre, que es el más antiguo que se conoce, integra una colección de 29 sentencias o veredictos. El Código de Hammurabi contiene 250 artículos, que el rey recibió del dios Samash, ${ }^{25}$ se remonta al s. XIX a.C. Antiguamente. ${ }^{26}$ Se regían también las relaciones médico-enfermo por normas específicas que se daban a sí mismos los profesionales de la medicina para el

\footnotetext{
${ }^{23}$ Cfr. Hooft, Pedro Federico, Bioética y Derechos Humanos, Desalma, Buenos Aires, 1999, p. 43.

${ }^{24}$ Cfr. Gary B., Sandy, 12,500 Frases célebres, grupo editorial Tomo I, México, 2005, p. 466.

${ }^{25}$ Samash, dios de la Justicia, es quien se las entrega a Hammurabi, rey de Babilonia. Aunque hay una serie de artículos dirigidos especialmente a los médicos, a los que impone sanciones penales para los casos de incumplimiento de las leyes, no se puede decir que sea, propiamente, un código deontológico.

${ }^{26}$ Lara Peinado, Federico y Lara González, Federico, Los primeros códigos de la humanidad, 2a edición, Technos, Madrid, España, 2009.
} 
mejor cumplimiento de sus funciones. Estas últimas son las que constituyen la deontología.

No muy distinta era la situación en el ámbito jurídico. Cuando se prescindió de la sociabilidad iusnaturalista como fundamento del derecho para adoptar una fundamentación contractualista más adecuada al individualismo moderno, será la protección de la vida el elemento clave (Hobbes) para crear el "pacta sunt servanda". ${ }^{27}$ Principio que actualmente soporta la Convención de Viena, ${ }^{28}$ y que se maneja de forma consuetudinaria ${ }^{29}$ que alimenta todo el ordenamiento jurídico ${ }^{30}$ en materia contractual, como el derecho civil, internacional y canónico.

A veces se duda en aceptar el término masculino "bioderecho" ${ }^{31}$ o el femenino "biojurídica" ${ }^{32}$ El segundo, a mi parecer es el más adecuado en su recorrido epistemológico y analítico de lo debido en nuevos proyectos jurídico/ positivos y es el de origen más antiguo, dentro de la relatividad de lo antiguo en una disciplina tan nueva. Indudablemente, se trata de una construcción con fuerte sabor italiano que es el origen del término. Por respetar la doble raíz griega, quizás fuese más correcto decir bionomótica, pero esta definición carece de aceptación y además, es un poco extraña.

Sin embargo, actualmente el bioderecho aborda el estudio de las realidades o fenómenos bioéticos desde la perspectiva del derecho positivo, en particular de las relaciones humanas bio-sanitarias. La biojurídica en cambio, aborda cuestiones bioéticas desde la perspectiva de la filosofía jurídica siendo su función principal justificar desde los principios éticos y jurídicos en los que se apoyara la norma jurídica, así como contar con la correcta interpretación de los preceptos jurídicos.

Es importante destacar que el derecho se apoya en juicios morales para delimitar cuáles de sus exigencias podrían considerarse jurídicas; por quedar vinculadas a una justicia como ajustamiento de las relaciones sociales capaces de

\footnotetext{
${ }^{27}$ Cfr. Ollero T., Andrés, Bioderecho, entre la vida y la muerte, Editorial Aranzadi, S.A., 2006, p. 15

${ }^{28}$ En materia internacional se señala que: "Todo tratado en vigor obliga a las partes y debe ser cumplido por ellas de buena fe" (según lo señala el artículo 26 de la Convención de Viena sobre el Derecho de los Tratados de 1969 y mismo artículo de la Convención de Viena sobre el Derecho de los Tratados celebrados entre Estados y Organizaciones Internacionales o entre Organizaciones Internacionales de 1986).

${ }^{29} \mathrm{Cfr}$. Kelsen, Hans, El contrato y tratado, analizados desde el punto de vista de la teoría pura del derecho, traducción de Eduardo Garcia Máynez, México, Imprenta Universitaria, 1943, p. 56.

${ }^{30} \mathrm{Kunz}$, Josef, The maening and the range of the norm Pacta Sunt Servanda, The American Journal of International Law, vol. 39, num. 2, april, 1945, Washington, D.C., pp. 180 y ss.

${ }^{31}$ Schaefer Rivabem, Fernanda, Biodireito: uma disciplina autônoma?, Rev. bioét. (Impr.). 2017; 25 (2): 282-9, Disponible en: http://dx.doi.org/10.1590/1983-80422017252188 05/10/2019

${ }^{32}$ Bonamigo Elcio, Luiz, El principio de precaución, un nuevo principio bioético y biojurídico, Publicia, 2015.
} 
posibilitar una convivencia digna del ser humano. Dentro del derecho circula la moral contenida en los principios o derechos humanos, ${ }^{33}$ también la percepción de alteridad que caracteriza todo fenómeno jurídico es lo más importante para una convivencia armónica ${ }^{34}$ y más aún de una coexistencia relacional proporcional y adecuada entre todas las personas.

Por los cambios dentro de la ciencia y las nuevas técnicas aplicadas a los seres humanos, se crea un nuevo ámbito del deber ser en el que se regulen las relaciones intersubjetivas a la luz de los principios de la bioética y la ciencia basada en evidencia. Las normas deberán ser jurídicas por su carácter coercitivo, para impedir al científico sucumbir a la tentación experimental de la presión de intereses económicos e ideológicos. Su objetivo es que no se desborden los cauces por los que transcurre el respeto a la vida, dignidad humana, identidad y libertad del ser humano, y no se vea afectada su esencia. De ahí se redefine una nueva rama del derecho "la biojurídica":

"Es la ciencia que tiene por objeto la fundamentación y pertinencia de las normas jurídico-positivas, de [lege ferenda] una ley a dictarse y de [lege data] una ley vigente, para lograr y verificar su adecuación a los principios y valores de la ética en relación con la vida humana, que es tanto como decir, su adecuación a los valores de la bioética”, ${ }^{35}$ de forma racional y proporcional.

El paso inmediato es establecer una jerarquía de bienes y valores desde el paradigma de la dignidad humana cuya excelsitud hace acreedora a la persona de la máxima consideración y que se tenga a la ciencia como simple instrumento a su servicio. ${ }^{36}$

Aplicar a las relaciones interpersonales los principios del derecho encierra los valores que en estratos vigentes se presentan a lo largo de la historia de la humanidad, que actualmente inspiró nuestro ordenamiento jurídico y que las Constituciones recogen en consonancia con los instrumentos internacionales garantes de derechos humanos, así como recomendaciones y códigos deontológicos encaminados al cuidado y preservación de la vida humana en un sentido amplio y coherente con los descubrimientos de la ciencia. Se hallaron así

\footnotetext{
${ }^{33}$ Alexy, Robert, El concepto y validez del derecho, Gedisa, Barcelona, 1997, p. 83, ver también Alexy, Robert, Derecho y Razón práctica, Fontamara, México, 2010 y Dworkin, Ronald, Los derechos en serio, Ariel, Barcelona, 1984.

${ }^{34}$ Idem. p. 16.

${ }^{35}$ Cfr. Vila-Coro, Maria Dolores, Introducción a la biojurídica, Servicio de publicaciones facultad de derecho de la Universidad Complutense de Madrid, 1995, p. 24.

${ }^{36}$ İdem. p.26
} 
los principios de la biojurídica a partir de los cuales se regulan por sí mismas las nuevas situaciones.

Asimismo, hay que saber que todo acto de autoridad debe encontrarse debidamente fundado y motivado. Fundado en el derecho válido y vigente, motivado con planteamientos lógico jurídicos racionales. Y esta rama del derecho también se tendrá que sustentar con la ciencia basada en evidencia, reconocida a nivel internacional, avalada por instituciones serias y objetivas debidamente comprobadas. Ya que la ciencia va estableciendo criterios sólidos, sin la posición de consenso, ni la creencia sobre la base de concepciones intelectuales más o menos lógicas, sino sobre hechos contrastados experimentalmente y demostraciones empíricas, develando cada vez más la realidad circundante.

La ciencia estipula teorías o hipótesis contrastables a nivel experimental o en algún nivel de la realidad empírica. Hace que su reproducibilidad de los experimentos (método) y sus resultados sean una constante, cuyos enunciados han resistido pruebas de refutación más severas o no han podido ser refutadas, corroborando sus enunciados en múltiples experimentos capaces de hacerlo. Enunciados testeables "Testability" (empirical hypothesis) a nivel de la realidad empírica y reproducible.

Por otro lado, todavía nos encontramos en un momento donde la ciencia jurídica avanza con estándares decimonónicos en su análisis a través de peritajes y amicus curiae, que en muchos sentidos conlleva intereses económicos o de una ideología. En ese sentido y siguiendo los principios pro-persona de exhaustividad, progresividad y evolución de los derechos humanos, dándole una importancia y peso específico a la interpretación evolutiva de los tratados, sobre la base de que "los tratados de derechos humanos son instrumentos vivos, cuya interpretación tiene que acompañar la evolución de los tiempos y las condiciones de vida actuales" y que dicha interpretación "es consecuente con las reglas generales de interpretación establecidas en el artículo 29 de la Convención Americana, así como en la Convención de Viena sobre el Derecho de los Tratados". ${ }^{37}$ De lo cual los avances científicos, basados en evidencia, brindan la base para su posterior interpretación.

Ahora bien, los principios que rigen a la biojurídica son los ya famosos y reconocidos principios del Derecho establecidos por Ulpiano:

\footnotetext{
${ }^{37} \mathrm{Cfr}$. El Derecho a la Información sobre la Asistencia Consular en el Marco de las Garantías del Debido Proceso Legal. Opinión Consultiva OC-16/99 de 1 de octubre de 1999. Serie A No. 16, párr. 114, y Caso Atala Riffo y Niñas Vs. Chile, párr. 83.
} 
1. Honeste vivere (vivir honestamente). Que la bioética trata como consentimiento informado, autonomía y objeción de conciencia.

2. Alterum non laedere (no dañar a otro). Que la medicina la reconoce como "primun non nocere" y la bioética con los principios de beneficencia y no maleficencia.

3. Ius sum quique tribuendi (dar a cada uno lo suyo de cada cual), que la bioética sostiene como el principio de justicia-símil en el derecho-.

Estos principios cuentan con dos pilares indispensables para la toma de decisiones principalmente en los temas relacionados con la utilización de biotecnología:

1. Prevención, que se debe observar cuando la aplicación del actuar médico o científico tiene consecuencias que se conocen y se demuestran, donde la evidencia científica no tiene duda de sus efectos dañinos al ser humano o cualquier otro ser vivo, $\mathrm{y}$

2. Precaución, ${ }^{38}$ cuando las consecuencias últimas son desconocidas, las acciones pueden llevarse a cabo con la debida prudencia para no caer en daños irreparables. Los ejemplos históricos sitúan el Principio de Precaución como la ponderación entre los bienes que se buscan para la vida humana y los riesgos que se corre de su aplicación en salud o medio ambiente, aunque no se tenga las pruebas necesarias para una evaluación definitiva.

El análisis de los riesgos y beneficios está así descrito por Vicente Belver Capella: ${ }^{39}$ En condiciones de incertidumbre la toma de decisiones razonables es la prudencia, ahora conocida en diversos documentos internacionales como el principio de precaución, entre otros, el tratado de Maastricht, la Declaración de Río sobre el Medio Ambiente y el Desarrollo, la Declaración de Asilomar y más recientemente en el 2006, un grupo de biólogos se reunieron en Berkeley,

\footnotetext{
${ }^{38}$ Para mayor información se puede consultar: Herrera Fragoso, Agustín Antonio, El Principio de Precaución como fundamento de la bioseguridad en la aplicación de alimentos transgénicos, Disponible en: http://biblat.unam.mx/ ca/revista/estudios-agrarios/articulo/el-principio-de-precaucion-como-fundamento-dehttp://biblat.unam.mx/ca/ revista/estudios-agrarios/articulo/el-principio-de-precaucion-como-fundamento-de-la-bioseguridad-en-la-aplicacion-de-alimentos-transgenicosla-bioseguridad-en-la-aplicacion-de-alimentos-transgenicos, consulta: 05-122014.

${ }^{39}$ Belver Capella, Vicente. Bioética y Ecología. en Tomas Garrido Gloria, M., Manual de Bioética. Barcelona: Editorial Ariel; 2001. p. 294.
} 
California, con el objetivo de llamar a un código voluntario de conducta que autorregule su trabajo. ${ }^{40}$

Las organizaciones que firman la carta abierta llaman a los que trabajan en biología sintética a abandonar sus propuestas de autorregulación y a que se comprometan en un proceso incluyente de debate social global sobre las implicaciones de su trabajo.

Hay que precisar que el derecho no aspira a determinar la verdad ontológica, pero sí a protegerla en la medida de los hechos que se tengan, caso en muchos casos se manipula para intereses diversos al fin adecuado, como es el caso, entre otros de: "pre-embrión en lugar de embrión, Organismos Genéticamente Modificados por transgénicos, muerte digna por eutanasia”, eufemismos muy usados dentro del derecho positivo.

Ahora bien, la Biojurídica como nueva disciplina; necesaria en el encausamiento de la norma jurídica de forma adecuada y proporcional en todos los temas referidos a la vida in genere y a la vida humana en particular precisa del auxilio de otras ciencias, ya que la estructura de los preceptos jurídicos requiere tres elementos: i) supuesto de hecho (p.e. la investigación sobre los embriones humanos), ii) el valor al que tiende la actividad (aplicación a los seres humanos realizando la justicia teniendo en cuenta el respeto a su dignidad) y iii) consecuencia jurídica dependiendo de que la actividad esté adecuada a lo establecido por el ordenamiento jurídico o, en caso contrario, se le aplique la sanción que corresponde ante el incumplimiento de la norma.

Así pues, para conocer exactamente el alcance de la investigación y la naturaleza de la realidad sobre la que se va a reflexionar es ineludible contar con conocimientos de ciencia basada en evidencia, una fundamentación antropológica, ética y el conocimiento de los preceptos del ordenamiento jurídico vigente aplicables al supuesto de hecho; en caso de que la norma no sea clara o no exista, se tendrán que dilucidar a través de los principios generales del derecho, el principio precautorio y de prevención, así como de los principios que actualmente se manejan dentro de la hermenéutica de los derechos humanos, como son el pro-persona, evolutivo, de progresividad y exhaustividad.

Es importante destacar que, es fundamental el concepto de persona que tengamos, ya que el conocimiento de la persona humana deberá ser integral y veraz, pues si el conocimiento es falso, limitado o parcial, la moralidad de las

\footnotetext{
${ }^{40}$ Información sobre la conferencia Synthetic Biology 2.0 y sus propuestas para autogobernarse, Disponible en: http://syntheticbiology.org, consulta: 16-07-2016.
} 
acciones será juzgada también con falsedad y el reconocimiento jurídico puede ser arbitrario limitado y por consecuencia discriminatorio.

En esa inteligencia, el principio de razonabilidad y proporcionalidad en la interpretación apunta precisamente a eso: exigir que el operador jurídico dé cuenta de las razones que lo condujeron a decidir cómo resolver en temas transdisciplinarios, de forma integral y siempre encaminando a la sindéresis (hacer el bien y evitar el mal), núcleo duro y sentido del derecho, para buscar la plenitud de la persona humana. De allí que una interpretación pueda ser irrazonable o arbitraria porque o bien esas razones no existen o bien existen, pero hay otras razones de mayor peso que deberían haber desplazado a las razones alegadas por el intérprete.

Por último, esta nueva rama del derecho también servirá para brindar una mejor argumentación en temas de derechos humanos, donde se está incursionando actualmente sobre estos temas, como se desprende de los siguientes instrumentos jurídicos en la materia:

i. La Declaración Universal sobre el Genoma Humano y los Derechos Humanos;

ii. La Declaración sobre las Responsabilidades de las Generaciones Actuales para con las Generaciones Futuras;

iii. La Declaración Universal sobre Bioética y Derechos Humanos, y

iv. El Convenio Europeo sobre los derechos humanos y la biomedicina.

La importancia y complemento del derecho en esta nueva rama, de cara al futuro y las nuevas tecnologías, es que sienta las bases desde las que se debe acometer la regulación de los conflictos de intereses que presentan los avances científicos en el campo principalmente de las biotecnologías, sin perder de vista la vida humana, con las connotaciones que por su condición de humana le son debidas, en la cumbre de la jerarquía de valores propias de un Estado de derecho democrático y garante de los derechos fundamentales.

\section{Conclusión}

A manera de corolario se puede señalar a la biojurídica como una nueva rama del derecho que utiliza la evidencia científica como soporte substancial para el análisis de los diversos supuestos de hecho, con la evidencia científica que se necesita para determinar casos de compatibilidad de trasplantes de órganos, los límites de la aplicación de una terapia proporcional, el momento de intervenir 
una operación intrauterina, el determinar la infertilidad de una pareja, cuántos embriones implantar en la fertilización asistida, etc.; los principios éticos, bioéticos y de derecho, brindan un soporte más objetivo y coherente en la aplicación de las nuevas investigaciones y aplicación de las tecnologías en la vida, en particular la vida humana, tomando muy en cuanta la parte axiológica del derecho, para la más adecuada ponderación en la toma de decisiones o para los casos difíciles a analizar. Así es como se observa actualmente en temas de: fertilización humana asistida, la clonación, la utilización de células progenitoras, manipulación genética, eugenesia, terapia génica, etc.

\section{Referencias Bibigráficas:}

ALEXY, ROBERT, El concepto y validez del derecho, Gedisa, Barcelona, 1997, p. 83.

ALEXY, ROBERT, Derecho y Razón práctica, fontamara, México, 2010.

BELVER CAPELLA VICENTE. Bioética y Ecologia. en Tomas Garrido Gloria M. Manual de Bioética. Barcelona: Editorial Ariel; 2001. p. 294.

BLÁZQUEZ, N., Bioética. La nueva ciencia de la vida. B.A.C. Madrid, 2000, p. 5.

BONAMIGO ELCIO, LUIZ, El principio de precaución, un nuevo principio bioético y biojurídico, Publicia, 2015.

D ` AGOSTINO, Francesco, Bioética estudios de filosofía del derecho, ética y sociedad, en ediciones internacionales universitarias, Madrid, 2003, p.14.

DURAND, GUY. La Bioética. Desclée de Brouwer. Bilbao, 1992.

DWORKIN, RONALD, Los derechos en serio, Ariel, Barcelona, 1984.

ENGELHARDT, H. T. La fundamentación de la bioética. Paidós. Barcelona, 1995.

GARY B., SANDY, 12,500 Frases célebres, grupo editorial Tomo I, México, 2005, p. 466.

GOLDIM, José Roberto, Revisiting the Beginning of Bioethics: The Contribution of Fritz Jahr (1927), Perspectives in Biology and Medicine 52, 2009, pp. 377-380.

HANS-MARTIN, Sass, Fritz Jahr's 1927 Concept of Bioethics, Kennedy Institute of Ethics Journal 17, 2008, pp. 279-295.

HOOFT, PEDRO FEDERICO, Bioética y Derechos Humanos, Desalma, Buenos Aires, 1999, p. 43.

JONAS, HANS, El Principio de responsabilidad: ensayo de una ética para la civilización tecnológica, edit. Herder, España, 1995.

KELSEN, HANS, El contrato y tratado, analizados desde el punto de vista de la teoría pura del derecho, traducción de Eduardo García Máynez, México, Imprenta Universitaria, 1943, p. 56.

KUNZ, JOSEF, The maening and the range of the norm Pacta Sunt Servanda, the american journal of international law, vol. 39, num. 2, april, 1945, Washington, D.C., pp 180 y ss.

LARA PEINADO, FEDERICO Y LARA GONZÁLEZ, FEDERICO, Los primeros códigos de la humanidad, $2^{\text {a }}$ edición, Technos, Madrid, España, 2009. 
LOLAS, FERNANADO, Bioethics and animal research. A personal perspective and a note on the contribution of Fritz Jahr, Biological Research 41 (2008), pp. 119-123.

NATACHA, Salomé Lima, Fritz Jahr y el Zeitgeist de la bioética, Aesthethika 5 (2009), pp. 4-11.

OLLERO T., ANDRES, Bioderecho, entre la vida y la muerte, Editorial Aranzadi, S.A., 2006, p. 15

PESSINA, A., Bioetica L'uomo experimental, Mondadori, Milano 1999, p. 3.

POTTER, V.R., Bioethics: Bridge to the future, Prentice-Hall Inc., Englewood Cliffs, New Jersey, 1971, pp. 1-2.

POTTER V.R. Biotethics the science of survival, Perspertives in Biology and Medicine, 14.1970, pp. 127-153; Bioethics: bridge to the future, Englewood Cliffs: Prentice-Hall,New York 1972.

RABELAIS, citado por MORÍN E. en el Método: La naturaleza de la naturaleza: Ediciones Cátedra. España, 6a edición, 2001.

REICH, W.T. (ed.), Encyclopedia of Bioethics I. The Free Press, New York 1978, XIX.

RUIZ RETEQUI, ANTONIO. La Ciencia y la fundamentación de la Ética. Deontología Biológica, Facultad de Ciencias, Universidad de Navarra, Pamplona, 1987.

SGRECCIA E., Manual de Bioética, Diana, México, 1996, p. 17.

SIMÓN VÁZQUEZ, CARLOS (director) Diccionario de bioética, editorial monte Carmelo, Burgos, España, 2006, p. 122.

TOMAS GLORIA, María y POSTIGO Solana, Elena (coordinadoras), Bioética Personalista: ciencia y controversias, Madrid, España 2007, p. 16.

VILA-CORO, MARÍA DOLORES, Introducción a la biojurídica, servicio de publicaciones facultad de derecho de la Universidad Complutense de Madrid, 1995, p. 24.

OTRAS FUENTES:

El Derecho a la Información sobre la Asistencia Consular en el Marco de las Garantías del Debido Proceso Legal. Opinión Consultiva OC-16/99 de 1 de octubre de 1999. Serie A No. 16, párr. 114, y Caso Atala Riffo y Niñas Vs. Chile, párr. 83.

El Derecho a la Información sobre la Asistencia Consular en el Marco de las Garantías del Debido Proceso Legal. Opinión Consultiva OC-16/99 de 1 de octubre de 1999. Serie A No. 16, párr. 114, y Caso Atala Riffo y Niñas Vs. Chile, párr. 83.

Información sobre la conferencia Synthetic Biology 2.0 y sus propuestas para autogobernarse, se puede consultar en: http://syntheticbiology.org, consulta: 16-07-2016.

HANS-MARTIN SASS Fritz Jahr's Bioethischer Imperativ. 80 Jahre Bioethik in Deutschland von 1927 bis 2007.Se puede consultar en: http://www.ethik-in-der-praxis.de/MM-175.pdf. 04-10-09.

HERRERA FRAGOSO, AGUSTÍN ANTONIO, El Principio de Precaución como fundamento de la bioseguridad en la aplicación de alimentos transgénicos, se puede consultar en: http://biblat.unam.mx/ca/revista/estudios-agrarios/articulo/el-principio-de-precaucion-como-fundamento-dehttp://biblat.unam.mx/ca/revista/estudios-agrarios/articulo/ 
el-principio-de-precaucion-como-fundamento-de-la-bioseguridad-en-la-aplicacion-de-alimentos-transgenicosla-bioseguridad-en-la-aplicacion-de-alimentos-transgenicos, consulta: 05-12-2014.

SCHAEFER RIVABEM, FERNANADA, Biodireito: uma disciplina autônoma?, Rev. bioét. (Impr.). 2017; 25 (2): 282-9, se puede consultar en: http://dx.doi. org/10.1590/1983-80422017252188 05/10/2019. 